\title{
Bacterial meningitis in Sudanese children; critical evaluation of the clinical decision using clinical prediction rules
}

\author{
Nada Abdelghani Abdelrahim ${ }^{*}$ (D), Imad Mohammed Fadl-Elmula ${ }^{2}$ and Hassan Mohammed Ali $^{3}$
}

\begin{abstract}
Background: Sudan falls in the meningitis belt where most global cases of bacterial meningitis are reported. Highly accurate decision support tools have been developed by international specialized societies to guide the diagnosis and limit unnecessary hospital admissions and prolonged antibiotic use that have been frequently reported from countries around the world. The goals of this study are to critically evaluate the clinical decision of bacterial meningitis in children in Sudan using clinical prediction rules and to identify the current bacterial aetiology.

Methods: This cross-sectional hospital-based study was conducted in October to July of 2010 in a major referral pediatric hospital in Khartoum, Sudan. Febrile children age 1 day to 15 years who were provisionally diagnosed as having meningitis on admission were included $(n=503)$. Cerebrospinal fluid (CSF) specimens were obtained from all patients while clinical and demographic data were available for only 404. Conventional laboratory investigations were performed. The clinical decision was evaluated by the International Classification of Diseases-Clinical Modification code 320.9 and the Bacterial Meningitis Score. Ethical clearance and permissions were obtained.

Results: Out of 503 provisionally diagnosed bacterial meningitis patients, the final clinical confirmation was assigned to 55.9\%. When codes were applied; 5.7\% (23/404) with CSF pleocytosis were re-classified as High Risk for bacterial meningitis and 1.5\% (6/404) with confirmed bacterial aetiology as Proven Bacterial Meningitis. Neisseria meningitidis was identified in $0.7 \%$ (3/404) and Streptococcus pneumoniae in another $0.7 \%$. Typical laboratory findings (i.e. CSF pleocytosis and/or low glucose and high protein concentrations, Gram positive or Gram negative diplococcic, positive bacterial culture) were seen in 5 (83\%). Clinically, patients showed fever, seizures, chills, headache, vomiting, stiff neck and bulging fontanelle. All confirmed cases were less than 5 years old and were admitted in summer. All patients were prescribed with antibiotics; they were all recovered and discharged.
\end{abstract}

Conclusions: Bacterial meningitis is over-diagnosed in hospitals in Khartoum therefore clinical prediction rules must be adopted and applied to guide the clinical decision. The sole bacterial aetiology in this selected group of Sudanese children remain N. meningitidis and S. pneumoniae, but with significant decrease in prevalence. Some cases showed atypical clinical and laboratory findings.

Keywords: Bacterial meningitis, Bacterial meningitis score, Children, Sudan

\footnotetext{
* Correspondence: nada.ghani@hotmail.com; nada.rahim@gmail.com

${ }^{1}$ Department of Pharmaceutics-Medical Microbiology, Faculty of Pharmacy, Nile University, Hai El-Gamaa, Al-Ailafoon Road, East Manshya Bridge, P.O. Box 11111, Khartoum, Sudan

Full list of author information is available at the end of the article
}

(c) The Author(s). 2019 Open Access This article is distributed under the terms of the Creative Commons Attribution 4.0 International License (http://creativecommons.org/licenses/by/4.0/), which permits unrestricted use, distribution, and reproduction in any medium, provided you give appropriate credit to the original author(s) and the source, provide a link to the Creative Commons license, and indicate if changes were made. The Creative Commons Public Domain Dedication waiver (http://creativecommons.org/publicdomain/zero/1.0/) applies to the data made available in this article, unless otherwise stated. 


\section{Background}

Bacterial meningitis (BM) can be a life-threatening emergency if not properly diagnosed and managed [1]. Over 1.2 million cases of BM are estimated to occur worldwide annually [2]. Incidence and case-fatality rates vary by region, country, pathogen and age group [3]. Case-fatality rate can be as high as $70 \%$ in untreated patients and 1 in 5 survivors may be left with permanent sequelae [3]. Therefore, BM is considered as one of the most feared childhood diseases. Consequently, the WHO developed recommendations for detecting BM epidemics in highly endemic countries in Africa (Alert and Epidemic definitions) [4, 5].

The epidemiology of BM has changed dramatically over the last 20 years, primarily as a result of the introduction of conjugate vaccines [1] against the commonest meningeal pathogens; Neisseria meningitidis, Streptococcus pneumoniae and Haemophilus influenzae [2]. Worldwide, the incidence of meningitis due to $N$. meningitidis is highest in the meningitis belt; a region of sub-Saharan Africa described as hyper-endemic and epidemics occurring during the dry season (December to June) $[5,6]$. Statistically, the incidence rate is 10 to 100 cases per $10^{5}$ populations punctuated by explosive epidemics in 8 to 12 year cycles with incidence rates that can be greater than $10^{3}$ cases per $10^{5}$ populations $[5,6]$. Across the meningitis belt, at least 350 million people are at risk for meningitis during these annual epidemics [6]. The climato-geographic location renders Sudan at permanent risk. A total of 15,595 cases including 1670 deaths due to $N$. meningitidis were reported from 4 countries in the meningitis belt in 2007 [7]. One of these countries was Sudan where 6946 cases with 430 deaths were reported from 9 out of 10 Southern states in the former Republic of Sudan [7]. About 1.1 million meningococcal vaccine doses were released in response to the outbreak in South Sudan targeting people in the affected areas in mass vaccination campaigns [7]. Mass vaccinations can lead to herd immunity resulting in dramatic reduction in infection rates among populations at risk [8]. The massive return of displaced Southerners to their homelands after the separation; where most areas fall in the meningitis belt, should have definitely affected the intensity and distribution of meningitis in the North; where minimum areas are considered to be within the doomed region.

Meningitis due to $S$. pneumoniae occurs most commonly in the very young and the very old, with an estimated incidence rate of 17 cases per $10^{5}$ in children less than 5 years, and case fatality rates that exceed $73 \%$ in some areas [9]. H. influenzae type b (Hib) is a major cause of infant and childhood meningitis [10]. Rates are highest in children less than 5 years reaching 31 cases per $10^{5}$ populations [10]. In young children, the case-fatality rate of Hib meningitis is generally higher than that for meningococcal meningitis [10]. Because of vaccination $[11,12]$ the burden of Hib meningitis is dramatically decreased in most industrialized countries and has been virtually eliminated as a public health problem [13]. We anticipate a comparable situation since Sudan has introduced Hib vaccines earlier than most developing countries and has maintained immunization coverage of $93 \%$ [13].

Distinguishing BM is often difficult [14] therefore several highly accurate decision support tools have been developed and validated to guide decision making and limit unnecessary hospital admissions and prolonged antibiotic use [14-16]. In Sudan, as in many other countries around the world, children who are suspected and provisionally diagnosed with meningitis are routinely admitted to hospitals and administered broad-spectrum antibiotics irrespective of culture and laboratory confirmation. Proper diagnosis of infectious CNS syndromes and the subsequent ability to distinguish BM is vital. This study aims at critically evaluating the hospital diagnosis of BM using internationally validated clinical prediction rules. We also aimed at studying the clinical parameters and identifying the type and frequency of bacterial aetiologies.

\section{Methods}

\section{Study design and ethical considerations}

This cross-sectional hospital-based study was conducted at a large central pediatric reference hospital in Khartoum, Sudan, during 10 months period (October to July, 2010). All febrile $\left(>37^{\circ} \mathrm{C}\right)$ attendees age 1 day to 15 years who were suspected of meningitis during the study period were included. Independent and dependent variables (demographic, clinical and conventional laboratory data and final outcome) were collected simultaneously in a pre-designed structured data sheet and kept anonymous. Ethical clearance was obtained from the Ethical Committee Board of Al-Neelain University. Permission to collect data was granted from hospital authorities. Patients were not contacted directly; data were obtained from hospital files.

\section{Study population and specimens}

Hospital case definition for suspected meningitis is: "sudden onset of fever, headache, stiff neck, episodes of seizure before or during admission and/or other symptoms as; nausea, vomiting, photophobia, altered mental status and coma". In newborns and young children: "General signs of being unwell as irritability, vomiting, poor feeding and/or bulging fontanelle". A confirmed case is: "a clinically compatible case that is laboratory confirmed by Gram stain and culture".

History of the current illness was evaluated upon admission by pediatricians and/or house-officers. Patients were inquired about self-medication with antibiotics 1 
week prior to lumbar punctures (LP) and contact with individuals with similar illness. Patients were examined clinically to evaluate onset of the classic symptoms: fever, headache, neck-stiffness, vomiting, bulging fontanelle, chills, seizures, altered mental status, skin rash, petechiae and coma. Demographic data included age and sex. Information recorded during hospital stay were: types of antibiotics administered, duration of hospital stay, final diagnosis and outcome. Total volumes of $3 \mathrm{ml}$ CSF were obtained from each patient via lumbar or ventricular puncture by hospital medical staff.

\section{Laboratory investigations}

Color and turbidity of CSF specimens were macroscopically inspected immediately upon withdrawal. Microscopical examination was performed on wet preparations and on Gram stained smears from the sediment. White cell count was performed in the non-centrifuged portions of specimens (diluted with an isotonic $0.1 \%$ toluidine blue, 1 in 2) using modified Fuchs-Rosenthal ruled counting chamber. CSF cell count was reported as cells $/ \mathrm{mm}^{3}$. When no white cells were seen, the count was reported as $<5$ cells $/ \mathrm{mm}^{3}$. Percentages of polymorphs and lymphocytes were estimated.

GlucoseOxidase/Peroxidase ${ }^{\circ}$ and Biuret $^{\circ}$ methods were used to measure CSF glucose level and CSF total proteins immediately upon collection using manual colorimetric methods and reagents (Biosystems ${ }^{\circ}$ ) following the supplier's protocols.

Irrespective of Gram stain result, all CSF specimens were cultured on Blood, Chocolate and MacConkey agar media. Inoculated cultures were incubated aerobically at $35^{\circ} \mathrm{C}$ overnight. Blood and Chocolate agar cultures were incubated in $\mathrm{CO}_{2}$ enriched atmosphere and kept for 72 h. Bacterial growth was examined daily and suitable biological and serological tests were applied to identify the aetiologic agent following the recommendations of Gray \& Fedorko [17] and Vandepitte et al [18].

\section{Secondary analysis using published clinical prediction rules}

Data collected throughout this study were used to distinguish $\mathrm{BM}$ according to the criteria listed in the Bacterial Meningitis Score (BMS) [14] which was later validated in the era of widespread pneumococcal vaccination [16] and the International Classification of Diseases-Clinical Modification Code 320.9 (ICD-CMC320.9) for BM [15]. These criteria aim at identifying infectious meningitis and distinguishing the bacterial condition in children with CSF pleocytosis. Following the criteria, meningitis suspected cases were re-classified as BM based primarily on CSF pleocytosis and the presence of at least one of the following indicators; seizures on or before presentation, other clinical signs of meningeal irritation, CSF absolute neutrophil count, CSF Gram stain and CSF protein concentration. Cases showing CSF pleocytosis were considered as Infectious Meningitis, those with one or more criteria of the BMS were considered as High Risk for BM, cases with in vitro culture confirmed bacterial aetiology were considered as Proven Bacterial Meningitis which was further specified as Meningococcal Meningitis when the isolated bacteria was Neisseria meningitidis or as Streptococcal Meningitis when it was Streptococcus pneumoniae.

\section{Statistical analysis}

The statistical package program SPSS version 21 was used. All numerical variables were organized into categories for better interpretation. Age obtained in days was converted into groups of neonates ( 1 to 29 days), infants (1 to 11 months), toddlers ( 1 to 5 years), children (6 to 10 years) and teenagers (11 to 15 years). All categorical variables were expressed in frequencies and percentages; high statistical significance $(p<0.001)$ for frequencies distribution was detected for each variable using the General Trend Analysis. Numerical variables were described using measures of central tendency and of dispersion. When Shapiro-Wilk Test of Normality was conducted, all data were found to be non-normally distributed; accordingly, nonparametric statistical tests were performed. Comparisons between categorical variables were done using cross-tabulations. Inferential statistics for statistically significant differences under the 0.05 level was applied using either Pearson Chi-square test; when 0 cells in the contingency table have expected count $<5$, or Fisher's Exact test; when $\geq 1$ cells in the table have expected count $<5$. Nominal by Nominal Phi and Cramer's V Correlation (Corre) along with its 95\% confidence intervals (CI) were obtained to assess possible relationships between categorical variables.

\section{Results}

\section{Demographic data}

A total of 503 patients were included. Patients arrived from different areas surrounding the hospital in Omdurman city and were all of low socio-economic class. Most admissions were in summer; a period extending from March to June (Fig. 1). Males represent 58.4\% (294/503). The median age of all children is 1.3 years with a range of 2 days to 15 years (i.e. $0.01-15.0$ years). Median age among males is 1.25 years $(\mathrm{IQR}=1.73 ; 0.01-15.0, n=$ 294 ) and among females is 1.33 years (IQR $=1.75 ; 0.02-$ $14.0, n=209)$. The most frequent age group was (1 to 5 years) among males (164/288 [6 missing], 56.9\%) and among females (125/208 [1 missing], 60.1\%), followed by age group (1 to 11 months) among males (104/288, $36.1 \%)$ and among females (76/208, 36.5\%). 


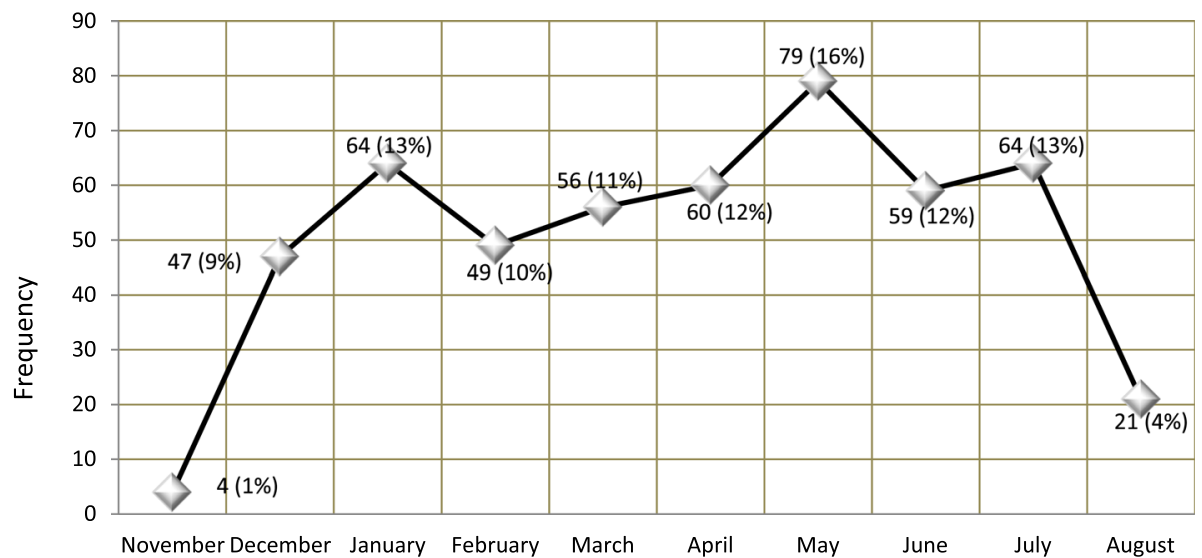

Fig. 1 Frequency of admissions to Omdurman Hospital for Children with suspicion of meningitis (Percentages were obtained out of 502 [1 case is missing])

\section{Clinical data}

The vast majority of cases with full records on clinical data ( $n=361 ; 28 \%$ [142 missing]) presented with fever and seizures, other symptoms are shown on (Table 1). All patients were never in close contact with family members or relatives with similar illness, they did not receive any type of antibiotics before hospital admission. Statistically significant differences but weak associations were obtained between fever and vomiting $(p=0.049$, Corre $=0.13$ [95\% CI: 0.03 to 0.23$]$ ). All 357 (71\% out of total 503) cases, with available hospital-stay data, did not suffer from complications and were discharged.

Statistically significant difference and association were obtained between age groups and headache $(p<0.001$, Corre $=0.4$ [95\% CI: 0.30 to 0.49]). Headache, naturally, was evaluated in 1 year olds and above where most patients $(65 \%, 15 / 23)$ were in age group $(1-5$ years), $13 \%$
$(3 / 23)$ in age group (6-10 years) and $22 \%(5 / 23)$ in age group ( $\geq 11$ years). Age groups and seizures showed significant difference $(p=0.046)$ but no association. Seizures were seen in all 4 patients in age group (1-29 days) and all 6 patients in (6-10 years), in 92.5\% (124/ $134)$ in age group (1-11 months), $93.3 \%(194 / 208)$ in age group (1-5 years) and $66.7 \%(6 / 9)$ in age group ( $\geq 11$ years). Highly significant difference was observed between season and stiff neck $(p=0.00)$ accompanied with significant but weak association (Corre $=0.23$ [95\% CI: 0.13 to 0.33$]$ ). The vast majority of those with stiff neck were admitted in summer $(15.2 \%, 31 / 204)$ and 3 in winter $(1.9 \%, 3 / 157)$. Statistical difference between season and bulging fontanelle (among $<1.5$ years olds) was detected with high significance $(p<0.001)$ and strong correlation (Corre $=0.54$ [95\% CI=: 0.43 to 0.64$]$ ). All cases with bulging fontanelle (age 0 to 18 months $[n=219]$ )

Table 1 Clinical data among patients with suspected meningitis and have available clinical data $(n=361)$

\begin{tabular}{llcc}
\hline Signs \& Symptoms & & Number of Cases & \% Out of 361 \\
1 & Fever & 355 & $98.3 \%$ \\
2 & Seizures & 334 & $92.5 \%$ \\
3 & Vomiting & 189 & $52.4 \%$ \\
4 & Chills & 63 & $17.5 \%$ \\
5 & Altered Mental Status & 36 & $10.0 \%$ \\
6 & Stiff neck & 34 & $9.4 \%$ \\
7 & Coma & 11 & $3.0 \%$ \\
8 & Skin Rash & 3 & $0.8 \%$ \\
9 & Petechiae & 2 & $0.6 \%$ \\
Signs \& Symptoms & & Number of Cases & Out of 309 \\
10 & Headache (for $>1$ year olds) & 23 & $7.4 \%$ \\
Signs \& Symptoms & & Number of Cases & \\
11 & Bulging Fontanelle (for $\leq 18$ months olds) & 37 & $20 \%$ \\
\hline
\end{tabular}


were admitted in summer $(30 \%, 37 / 124)$. No significant differences and associations were found between the remaining demographic and clinical data.

Based on hospital records; $61.8 \%(220 / 356)$ of all admissions during the study period were diagnosed as having a CNS associated condition; 55.9\% (199/356) as bacterial (septic) meningitis, $0.6 \%(2 / 356)$ brain abscess and $5.3 \%(19 / 356)$ febrile convulsions. The remaining $38.2 \%(136 / 356)$ were diagnosed as having other infections; data is provided in the Additional file 1 . High significance $(p<0.001)$ but weak association (Corre $=0.27$ [95\% CI: 0.19 to 0.35]) were observed between hospital diagnosis and season of admission. On cross-tabulations; amongst patients diagnosed as having BM, 50.3\% (100/199) were admitted in summer and $49.8 \%(99 / 199)$ in winter. All patients were treated during hospitalization by first line and/or second line antibiotic therapies (Table 2).

\section{Hospital-stay data}

Period of hospital stay was evaluated; median 6 days with range of 1 to 38 days. Highly significant and strong positive association $(p<0.001$, Corre $=+0.77$ [95\% CI: 0.72 to 0.81]) were identified between the duration of hospital stay and final hospital diagnosis. Findings of cross-tabulations are summarized on Table 3.

\section{Conventional laboratory data}

All of the 503 patients were subjected to LP, nevertheless, $8.8 \%(44 / 503)$ of the withdrawn CSF specimens were traumatic, therefore, cytological and chemical analyses were not performed. The vast majority $(94.8 \%, 383 /$ 404) of CSF specimens that were non-traumatic showed no WBCs $\left(<5\right.$ cells $\left./ \mathrm{mm}^{3}\right)$. Significant WBC count $(\geq 5$ cells $/ \mathrm{mm}^{3}$ ) was identified in 5.2\% (21/404). Median CSF cell count for values above 5 cells $/ \mathrm{mm}^{3}$ was 3000 with range of 50 to 33,400 cells. CSF specimens with high WBC count ( $>100$ cells $/ \mathrm{mm}^{3}$ ) showed neutrophilic predominance; reaching in average $80 \%$ and those with low WBC count $\left(\leq 100\right.$ cells $\left./ \mathrm{mm}^{3}\right)$ showed lymphocytic predominance; reaching 60\%. Abnormal CSF glucose concentration $(<45$ or $>100 \mathrm{mg} / \mathrm{dl})$ was seen in $11.9 \%(54 /$ 453). Abnormal CSF protein concentration $(<14$ or $>45$ $\mathrm{mg} / \mathrm{dl}$ ) was seen in $47.7 \%$ (215/451). Direct Gram stain preparation showed Gram positive diplococci in $0.7 \%$ (3/ 451 [52 missing]) and Gram negative diplococci in another $0.7 \%$. On CSF culture for rapidly growing bacteria, all specimens that were Gram positive on direct preparations yielded S. pneumoniae $(0.7 \% ; n=3)$ and all those that were Gram negative yielded $N$. meningitidis $(0.7 \%$; $n=3)$. A single bacterium was isolated from each patient; there were no polymicrobial infections. Two out of the $3(66.7 \%) N$. meningitidis isolates were identified as W135 serotype. Further laboratory data is provided in the Additional file 1.

\section{Findings on cases with positive bacterial aetiology Streptococcus pneumoniae}

All 3 patients with positive bacterial culture for S. pneumoniae presented with fever and seizures; 1/3 (33.3\%) suffered also from chills, vomiting, bulging fontanel and altered mental status. She was the only female. They were all infants (1-11 months). The female and 1 of the 2 males $(66.7 \%)$ were admitted in summer; the third in winter. The female CSF was bloody; the rest were turbid. Turbid specimens showed high CSF WBC count $(\geq 1000$ cells $/ \mathrm{cmm}^{3}$ ) and all showed neutrophilic predominance $(\geq 70 \%)$. All specimens had low CSF glucose level $(<45$ $\mathrm{mg} / \mathrm{dl}$ ) and high CSF proteins level $(>45 \mathrm{mg} / \mathrm{dl})$. All 3 patients had a confirmed hospital diagnosis of bacterial

Table 2 Prescriptions during hospitalization

\begin{tabular}{|c|c|c|c|}
\hline \multicolumn{2}{|c|}{ Antibiotic Prescription During Hospitalization } & Number of Cases & $\%$ Out of 354 \\
\hline \multicolumn{4}{|c|}{ First Line Antibiotic Therapy (All of the 354 cases) } \\
\hline 1 & Ampicillin & 186 & $52.5 \%$ \\
\hline 2 & Penicillin & 89 & $25.2 \%$ \\
\hline 3 & Cephalosporin & 78 & $22.0 \%$ \\
\hline 4 & Quinin & 1 & $0.3 \%$ \\
\hline \multicolumn{2}{|c|}{ Antibiotic Prescription During Hospitalization } & Number of Cases & $\%$ Out of 189 \\
\hline \multicolumn{4}{|c|}{ Second Line Antibiotic Therapy (189 out of the 354 cases) } \\
\hline 5 & Ampicillin & 1 & $1 \%$ \\
\hline 6 & Penicillin & 2 & $1 \%$ \\
\hline 7 & Cephalosporin & 165 & $87 \%$ \\
\hline 8 & Chloramphenicol & 8 & $4 \%$ \\
\hline 9 & Gentamycin & 4 & $2 \%$ \\
\hline 10 & Quinin & 9 & $5 \%$ \\
\hline
\end{tabular}


Table 3 Hospital-stay data

\begin{tabular}{|c|c|c|c|c|c|}
\hline Duration of Hospital Stay & Bacterial Meningitis & Brain Abscess & Febrile Convulsions & Non CNS Infections & Number of Cases \\
\hline 1 to 3 Days Stay in Hospital & $11 / 186(5.9 \%)$ & $1 / 2(50 \%)$ & $8 / 19(42 \%)$ & $94 / 134(70.1 \%)$ & 114 \\
\hline 4 to 7 Days Stay in Hospital & $41 / 186(22 \%)$ & $1 / 2(50 \%)$ & 9/19 (47.4\%) & $36 / 134(26.9 \%)$ & 87 \\
\hline 8 to 14 Days Stay in Hospital & 129/186 (69.4\%) & - & $1 / 19(5.3 \%)$ & $3 / 134(2.2 \%)$ & 133 \\
\hline 15 to 30 Days Stay in Hospital & $4 / 186(2.2 \%)$ & - & $1 / 19(5.3 \%)$ & $1 / 134(0.8 \%)$ & 6 \\
\hline More than 30 Days Stay in Hospital & $1 / 186(0.5 \%)$ & - & - & - & 1 \\
\hline Number of Cases (\% Out of 356) & $199^{\mathrm{a}}(55.9 \%)$ & $2(0.6 \%)$ & $19(5.3 \%)$ & $136^{\mathrm{b}}(38.2 \%)$ & \\
\hline
\end{tabular}

${ }^{a}$ Missing data for 13 cases among those with Bacterial Meningitis; the denominator for percentages among Bacterial Meningitis is 186

${ }^{\mathrm{b}}$ Missing data for 2 cases among those with Non CNS Infections; the denominator for percentages among Non CNS Infections is 134

meningitis. They were all treated with penicillin, ampicillin and/or cephalosporins. Further data is provided in the Additional file 1.

\section{Neisseria meningitidis}

All the same, all 3 patients presented with fever and seizures. One of the 3 (33.3\%); a toddler in the age group (1-5 years), suffered also from headache and vomiting. The remaining 2 (66.7\%) infants (1-11 months) presented also with chills, 1 (33.3\%) of them with vomiting and the other with stiff neck and bulging fontanel. $N$. meningitidis serotype W135 was identified in the isolates from the two infants. All patients were females, they all admitted in summer. Non typical conventional laboratory results were seen; the case that was presented with only 4 symptoms had a clear CSF, normal WBC count ( $<5$ cells $/ \mathrm{mm} 3)$, normal CSF glucose level $(45-100 \mathrm{mg}$ / $\mathrm{dl})$, and normal CSF protein level $(14-45 \mathrm{mg} / \mathrm{dl})$. The second infant had a traumatic CSF; therefore, no cytological or chemical analyses were performed. The toddler's CSF WBC count revealed leukocytosis ( $>1001$ cells/mm3); low CSF glucose level $(<45 \mathrm{mg} / \mathrm{dl})$ and high CSF protein level $(>45 \mathrm{mg} / \mathrm{dl})$. All patients had a confirmed hospital diagnosis of septic meningitis. They were all treated with penicillin or ampicillin and cephalosporins. Further data is provided in the Additional file 1.

\section{Secondary analysis using clinical prediction rules}

Data on the 5th criterion (Peripheral Blood Absolute Neutrophil Count $\geq 10,000$ Cells $/ \mu \mathrm{L}$ ) of the BMS was unavailable; therefore, 4 criteria were used in this analysis. When 1 or more prediction rules were fulfilled, patients were considered at High Risk of BM (Table 4). Patients having none of the High Risk criteria were considered at Low Risk of BM. All findings are described on Tables 4 and 5 and Fig. 2.

\section{Discussion}

In reference to the data from hospital records, BM was assigned for $56 \%$ of the study population. This number seems to be exaggerated since neither an Alert nor an Epidemic [5] of BM was announced by National and/or International authorities in Sudan at the time of the study. In fact, a much smaller figure of $1.5 \%$ was later identified as Proven Bacterial Meningitis when codes and criteria were followed (Table 5). A total of 40 cases out of the study population were found to either have Proven Infectious Meningitis or are Highly Suspected to have the disease. Accordingly the proportion of those with proven infectious meningitis among our study population would be $10 \%$ (Table 5). We found this figure to be rather diluted because of the wide denominator i.e. provisional diagnosis of infectious CNS disease was too inclusive. This shortcoming is not only limited

Table 4 Five high-risk criteria of the bacterial meningitis score

\begin{tabular}{|c|c|c|c|}
\hline \# & $\begin{array}{l}\text { High-Risk criteria for } \\
\text { bacterial meningitis }\end{array}$ & $\begin{array}{l}\text { Number of cases out } \\
\text { of } 23 \text { with Pleocytosis }\end{array}$ & $\begin{array}{l}\text { Number of cases out of total with } \\
\text { available data per each variable }\end{array}$ \\
\hline 1 & Positive CSF Gram stain & 6 & 6 out of 451 \\
\hline 2 & $\mathrm{CSF} \mathrm{ANC}^{\mathrm{b}} \geq 1000$ cells $/ \mu \mathrm{L}$ & $19^{c}$ & 19 out of 404 \\
\hline 3 & CSF protein $\geq 80 \mathrm{mg} / \mathrm{dl}$ & 19 & 25 out of 451 \\
\hline 4 & Peripheral blood ANC $\geq 10,000$ cells/ $\mu \mathrm{L}$ & $\operatorname{NAD}^{\mathrm{d}}$ & NAD \\
\hline 5 & Presence of seizure at or before presentation & 19 & 334 out of 361 \\
\hline
\end{tabular}

a Pleocytosis is defined as CSF cell count $>5$ cells $/ \mathrm{mm}^{3}$

${ }^{\mathrm{b}}$ ANC: Absolute Neutrophil Count

'Count of N\% from 68 to $100 \%$ in samples with CSF cell count of $\geq 1001$ cells/ $\mathrm{LL}$

dNAD: Data Not Available

The Bacterial Meningitis Score developed by Nigrovic et al. (2002) [14] 
Table 5 Re-classification according to the bacterial meningitis score and the international classification of diseases - code for bacterial meningitis

\begin{tabular}{|c|c|c|c|c|}
\hline & \multirow[t]{2}{*}{ Re-classification } & \multicolumn{2}{|c|}{ Cases out of $404^{a}$} & \multirow{2}{*}{$\begin{array}{l}\% \text { Out } \\
\text { of } 40\end{array}$} \\
\hline & & $\%$ & Frequency & \\
\hline 1 & Proven Infectious Meningitis & $10 \%$ & $40^{b}$ & $100 \%$ \\
\hline 2 & Proven Bacterial Meningitis & $1.5 \%$ & 6 & $15 \%$ \\
\hline 3 & Meningococcal meningitis & $0.7 \%$ & 3 & $7.5 \%$ \\
\hline 4 & Pneumococcal meningitis & $0.7 \%$ & 3 & $7.5 \%$ \\
\hline \multicolumn{5}{|c|}{$\begin{array}{l}\text { a Total number of febrile patients who attended the hospital during the study } \\
\text { period and were subjected to LP were } 503, \text { however, } 404 \text { is determined as the } \\
\text { denominator because of complete bacteriology and clinical data } \\
{ }^{b} 17 \text { cases with positive microbial origin -but with normal cellular count-along } \\
\text { with all the } 23 \text { cases with CSF pleocytosis. Findings on microbes that are not } \\
\text { rapid-growing-bacteria will be revealed in other publications }\end{array}$} \\
\hline
\end{tabular}

to hospitals in Khartoum since several articles from around the world reported almost similar findings. The proportion of children who were proved to have meningitis by laboratory confirmation was always around 50\% or less among those who were highly suspected and subjected to LP. Studies from the developing world reported much less estimates that are closer to ours. A study conducted in pediatric hospitals in Iran has identified meningitis in $16.8 \%(65 / 387)$ [19]. Countries falling in the meningitis belt reported small estimates as well. Laboratory confirmed cases among suspects during 5 years in Burkina Faso were 22\% (4503/20,389) [20], 24\% (279/ 1176) during 6 years in Ghana [21] and 26\% (871/3306) in 20 years surveillance in Mali [22]. Studies in developed countries reported different results. Amarilyo et al [23] reported 54\% (58/108) among meningitis suspected children. Other studies conducted by Dubos et al [24], Oostenbrink et al [25], Bonsu et al [26] and Oostenbrink et al [27] in children who underwent LP have reported comparable findings $(\approx 40 \%$ prevalence of meningitis $)$.

\section{All (503) suspected cases}

$\downarrow$ (99 MD)

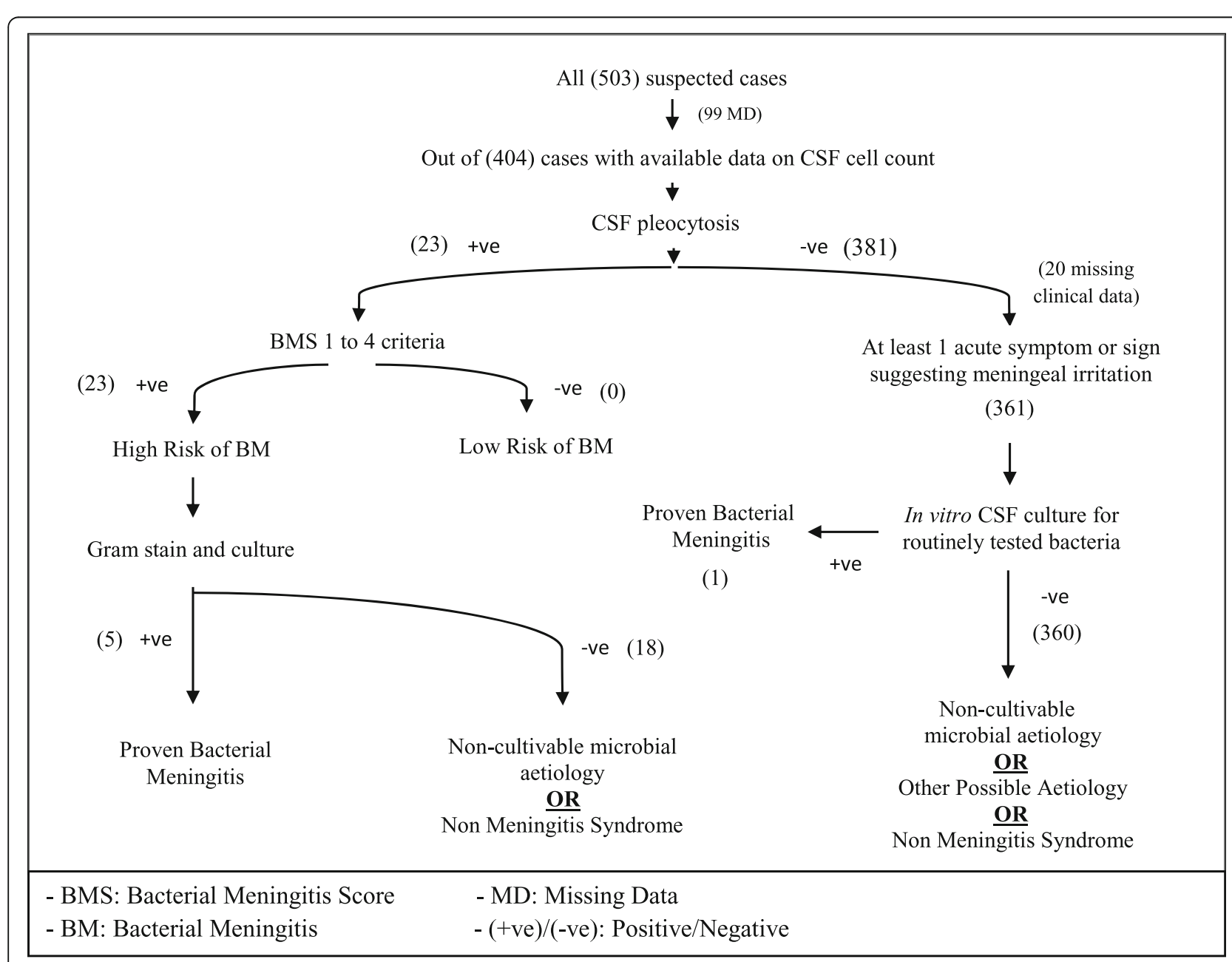

Fig. 2 Categorization of all cases based on the Bacterial Meningitis Score and the International Classification of Diseases - Code for Bacterial Meningitis 
The corresponding low value we obtained from hospital records could be attributed to lack of strict adherence to meningitis criteria, a situation that appears to be common in hospitals in developing countries. We identified only $1.5 \%$ as proven $\mathrm{BM}$ which was closely in agreement with published reports where only $3.7 \%(n=122)$ were identified in the study of Nigrovic et al [16] among 3295 children with CSF pleocytosis. Among highly suspected cases in our study, however, a higher figure of $15 \%$ was identified as BM. This was in good agreement with previous published reports. Dubos et al [28] and Amarilyo et al [23] identified $12 \%(20 / 166)$ and $10.3 \%(6 / 58)$, respectively, as BM among suspected patients in pediatric emergency units. Similarly, Bonsu et al [26] and Oostenbrink et al [27] identified a maximum of $20 \%$. In contrast, a national Polish survey identified bacterial aetiology in $40 \%(980 / 2475)$ of cases with neuroinfections in 1 year [29]; most probably a result of an outbreak in Poland.

When it comes to diagnosing a debilitating and potentially fatal illness in a pediatric population of a country located in the meningitis belt, health care officers in Sudan often tend not to dismiss a poorly suspected case. Fear of misdiagnosis or late treatment result in over diagnosis that could lead to an increased hospitalization costs as evident by the extended periods of hospitalizations (Table 3). Over diagnosis can also lead to the emergence of drug-resistant strains due to antibiotics overuse, and hence the accuracy of the national health registry becomes questionable. Therefore, the ability to monitor simple seasonal rise in disease incidence, identifying an actual epidemic and implementing the appropriate control measures will consequently be affected.

Pneumococcal and meningococcal conditions were equally identified in $7.5 \%$ among those with proven infectious meningitis in this study. A recent metaanalysis [30] covering 56 studies identified S. pneumoniae and $N$. meningitidis as the predominant pathogens of BM in children of all ages in all regions. In previous studies, pneumococcal disease was usually identified in relatively small number of cases. Dubos [28] reported 5\% (9/166) S. pneumoniae meningitis among patients with CSF pleocytosis. Even though in a meningitis outbreak situation, only $6 \%(n=149)$ was reported as S. pneumoniae among $40 \%$ with bacterial aetiology [29]. Never the less, the aforementioned meta-analysis reported $S$. pneumoniae as the most common cause of BM in children ranging from $22.5 \%$ in Europe and $41.1 \%$ in Africa [30]. A reduction in meningococcal meningitis occurrence was reported in Burkina Faso [20] and Ghana [21], where Dubos [28] and Turczyńska [29] identified N. meningitidis in 5\% $(9 / 166)$ and 9\% (220/2475) respectively, closely comparable to our findings of $7.5 \%$. On the other hand, studies in Mali reported 44\% meningococcal meningitis and $31 \%$ pneumococcal meningitis [22].

All our patients were admitted in the high risky season that is described climatologically as dry compared to about $65 \%$ of all cases that were recorded in the Ghanaian study in this season [21]. This period constitutes the peak of meningococcal disease occurrence, unlike the pneumococcal occurrence that varies seasonally [31, 32]. In this study, all meningococcal patients were less than 5 years, an age group that has the highest reported incidence rate $[30,33]$. Pneumococcal meningitis occurs most commonly in the very young and the very old [9], where all cases we have studied were infants aged 1 to 11 months. Fortunately, all of them have recovered and discharged despite reports on high case-fatality rates [9].

Diagnostic signs for BM in young children are unclear; they do not often exhibit the general symptoms and may only be irritable and look unwell [34]. All cases with proven $\mathrm{BM}$ in this study presented with high fever and seizures. Other classic symptoms, namely, neck stiffness, chills and bulging fontanelle, were seen in one third of the children only. Bulging fontanelle and admission in summer were the only parameters that showed significant statistical difference and strong association. An inflammation in the brain or the meninges can cause a bulging fontanelle [34]. Amongst the several aetiologies bacteria and viruses are the most common and these occur more frequently in summer [34]. The fact that all $37(20 \%)$ patients who suffered from a bulging fontanelle (Table 1) presented in summer strongly suggests a microbial aetiology. However, only 2 (33.3\%) of our 6 BM confirmed cases presented the symptom. In the study of Amarilyo et al [23], bulging fontanelle was present in $50 \%$ of patients with meningitis and had a positive predictive value of only $38 \%$. Several studies have reported atypical clinical findings in young patients with BM of either meningococcal or pneumococcal aetiology [23, 35]. In fact, a guideline describing these anomalies was established [36]. Amarilyo [23] recommended that these clinical indicators should not be the sole determinants for referral to further diagnostic testing and LP.

Typical findings on CSF analysis [37, 38] were seen in all cases with $S$. pneumoniae and in only one third with $N$. meningitidis, while another third showed normal CSF picture. Normal CSF cellular count in those with positive CSF culture can be demonstrated, however, rarely [39]. Garges et al [40] concluded that BM in babies frequently occurs in the presence of normal CSF parameters, including WBC count [40].

Hib was not identified in this study probably as the result of the introduction of Hib vaccine to the pediatric population in Sudan which was first started in 1976 and later on in 2001 [13]. Following critical review of accessible publications, this finding is in conformity. The study 
from Burkina Faso reported H. influenzae in a small proportion of $2 \%$ [20] and Ghana did not identify the bacterium amongst other aetiologies of BM in children [21]. Further, Strange [41] affirmed that $H$. influenzae meningitis in children has become so rare that a case could hardly be seen. The study of Dubos [28] identified only one case with Hib meningitis (0.6\%) among 166 BM suspected patients and the prospective French nationwide survey of Bingen et al [42] detected $H$. influenzae in only $2.5 \%$ (27/1084). Amongst published articles within our reach were those from Mali which stated that the country has suffered high morbidity and mortality of BM and high occurrence of $H$. influenzae meningitis [22, 43]. Hib conjugate vaccine was first introduced to children in Mali in 2005 to 2007 [43]. In 20 years surveillance (1996-2016) Mali reported $H$. influenzae in 23\% [22] and a post vaccination evaluation [43] identified a decrease of $86 \%$ of Hib among high risk infants of 6 to 7 months old and an overall annual incidence drop of $74 \%$ by the second year. All the aforementioned studies, including those from Mali, and many others along with ours confirm the notion that Hib meningitis is about to be eliminated. It is worth mentioning that the Federal Ministry of Health in Sudan has been demonstrating strong commitment and good adherence to vaccination programmes provided by UNICEF and WHO [13]. The observed absence of Hib infections and the great reduction in conditions of BM caused by all other aetiologies are closely comparable to that reported by Schuchat [12] and fairly places Sudan in a better position regarding the control of such disease compared to other African countries.

\section{Conclusions}

In conclusion, the study has indicated a significant reduction in the occurrence of BM. S. pneumoniae and N. meningitidis are the sole pathogens of pediatric $\mathrm{BM}$ and $H$. influenzae is no longer an aetiology. Many cases showed atypical clinical and laboratory findings. Codes and criteria for the diagnosis of $\mathrm{BM}$ are not followed and that consequence leads to over-diagnosis and overprescription of antibiotics. It is therefore of paramount importance that the decision of BM should be guided by internationally validated clinical prediction rules.

\section{Additional file}

Additional file 1: Supplementary materials are provided in the file: BM in Children in Sudan (Supplementary Material). It includes 3 tables in the following order. Hospital Diagnosis (Non CNS Conditions): Shows frequencies and percentages of cases diagnosed by the hospital as having conditions affecting systems other than the CNS. Conventional Laboratory Data: Demonstrates detailed laboratory findings for all cases. Findings on Cases with Positive Bacterial Aetiology: Shows detailed findings for cases with confirmed bacterial meningitis. (DOCX 27 kb)

\section{Abbreviations}

ANC: Absolute Neutrophil Count; BM: Bacterial Meningitis; BMS: Bacterial Meningitis Score; Cl: Confidence Interval; CNS: Central Nervous System; Corre: Nominal by Nominal Phi and Cramer's V Correlation;

CSF: Cerebrospinal Fluid; H. influenzae: Haemophilus influenzae; Hib: Haemophilus influenzae type b; ICD-CMC: International Classification of Diseases - Clinical Modification Code; IQR: Inter Quartile Range; LP: Lumber Puncture; MD: Missing Data; Mdn: Median; N. meningitidis: Neisseria meningitidis; NA: Not Applied; NAD: Data Not Available; S.

pneumoniae: Streptococcus pneumoniae; SD: Standard Deviation; UNICEF: United Nations International Children's Emergency Fund; WHO: World Health Organization

\section{Acknowledgements}

We sincerely acknowledge efforts exerted by the Writing Papers Workshop-2017 of the International Brain Research Organization (4th IBRO-Arc) that was organized and tutored by Prof. Marina Bentivoglio, Dr. Krister Kristensson and colleagues; without their generous assistance and guidance this paper would have never seen the light. We thank the laboratory technologists in the bacteriology departments of Omdurman Hospital for Children, the National Health Laboratory and the Central Public Laboratories at the Ministry of Health for providing accessibility to clinical data and specimens. We appreciate the generous advice in statistics that was provided by Dr. Elshibli Elshibli.

\section{Authors' contributions}

NA developed research questions and design, collected and managed all data, performed all statistical analysis and interpretation, wrote and edited the text. IF supervised the research process throughout; contributed in the development of research questions, design and methodology, managed all logistics and clinic based activities, advised on analysis and led interpretation of results and was a major contributor in developing the manuscript. HA contributed to the design, advised on the approach and methodology, edited and proofread the manuscript substantially. All authors read and approved the final manuscript.

Funding

We received no financial support for the research, authorship and/or publication of this article.

\section{Availability of data and materials}

The dataset used during the current study will be available from the corresponding author on reasonable request.

\section{Ethics approval and consent to participate}

The ethical clearance for conducting this study was obtained from the Ethical Committee Board of Al-Neelain University. Permission to collect data was granted from hospital authorities. Patients were not contacted directly; data were obtained from hospital files and were kept anonymous at all stages of the study.

\section{Consent for publication}

Not applicable.

\section{Competing interests}

The authors declare that they have no competing interests.

\section{Author details}

'Department of Pharmaceutics-Medical Microbiology, Faculty of Pharmacy, Nile University, Hai El-Gamaa, Al-Ailafoon Road, East Manshya Bridge, P.O. Box 11111, Khartoum, Sudan. ${ }^{2}$ Department of Pathology \& Clinical Genetics, Alneelain University \& Assafa Academy, Khartoum, Sudan. ${ }^{3}$ Department of Clinical Pharmacology, Faculty of Pharmacy, National University-Sudan, Khartoum, Sudan.

Received: 16 January 2019 Accepted: 21 August 2019

Published online: 06 September 2019

\section{References}

1. Nudelman Y, Tunkel A. Bacterial meningitis: epidemiology, pathogenesis and management update. Drugs. 2009;69(18):2577-96. 
2. World Health Organization and Office of Information. Epidemic meningococcal disease. WHO fact sheet. Geneva: World Health Organization; 1998.

3. Rosenstein N. Meningococcal disease. N Engl J Med. 2001;344(18):1378-88,

4. World Health Organization and Office of Information. Recommendation of a consensus meeting on detection of meningitis epidemics in Africa. Paris: World Health Organization; 2000.

5. World Health Organization. Detecting meningococcal meningitis epidemics in highly-endemic African countries. Geneva: World Health Organization; 2000.

6. World Health Organization. Managing meningitis epidemics in Africa a quick reference guide for health authorities and health-care workers. Geneva: World Health Organization; 2010.

7. World Health Organization. WHO vaccine-preventable diseases monitoring system: 2007 global summary, ed. D.o.l. World Health Organization, Vaccines Biologicals. Geneva: World Health Organization; 2007.

8. Rashid H, Khandaker G, Bryan J. Vaccination and herd immunity: what more do we know? Curr Opin Infect Dis. 2012;25(3):243-52.

9. O'Brien K. Burden of disease caused by Streptococcus pneumoniae in children younger than 5 years: global estimates. Lancet. 2009;374(9693): 893-902.

10. Watt J. Burden of disease caused by Haemophilus influenzae type $b$ in children younger than 5 years: global estimates. Lancet. 2009;374(9693): 903-11.

11. Swingler G, Fransman D, Hussey G. Conjugate vaccines for preventing Haemophilus influenzae type b infections. Cochrane Database Syst Rev. 2003:4:CD001729.

12. Schuchat A. Bacterial meningitis in the United States in 1995. Active Surveillance Team. N Engl J Med. 1997;337(14):970-6.

13. World Health Organization. WHO vaccine-preventable diseases monitoring system: 2010 global summary, ed. Dept of Immunization-Vaccines Biologicals. Geneva: World Health Organization; 2010.

14. Nigrovic L, Kuppermann N, Malley R. Development and validation of a multivariable predictive model to distinguish bacterial from aseptic meningitis in children in the post-Haemophilus influenzae era. Pediatrics. 2002:110(4):712-9.

15. Hart A, Hopkins CA. 2001 ICD-9-CM Code Book. Reston: St. Anthony Publishing and West Valley City, UT: Ingenix; 2000.

16. Nigrovic L. Clinical prediction rule for identifying children with cerebrospinal fluid pleocytosis at very low risk of bacterial meningitis. JAMA. 2007;297(1):52-60.

17. Gray L, Fedorko D. Laboratory diagnosis of bacterial meningitis. Clin Microbiol Rev. 1992;5(2):130-45.

18. Vandepitte J. In: Rohner P, Engbaek K, Piot P, Heuck C, editors. Basic laboratory procedures in clinical bacteriology. 2nd ed. Geneva: World Health Organization; 2003. p. 167

19. Hosseininasab A. Viral etiology of aseptic meningitis among children in southern Iran. J Med Virol. 2011;83(5):884-8.

20. Diallo AO, Soeters HM, Yameogo I, Sawadogo G, AkeÂ F, Lingani C, Wang X, Bita A, Fall A, SangareÂ L, OueÂdraogo-Traorê̂A R, Medah I, Bicaba B, Novak RT. Bacterial meningitis epidemiology and return of Neisseria meningitidis serogroup a cases in Burkina Faso in the five years following MenAfriVac mass vaccination campaign. PLoS One. 2017;12(11):e0187466. https://doi. org/10.1371/journal.pone.0187466.

21. Kaburi BB, Kubio C, Kenu E, Ameme DK, Mahama JY, Sackey SO, Afari EA Evaluation of bacterial meningitis surveillance data of the northern region, Ghana, 2010-2015. Pan Afr Med J. 2017;27:164. https://doi.org/10.11604/ pamj.2017.27.164.11036.

22. Coulibaly S, Keita A, Guindo I, Abdou M, Dao K, Cisse I, Samake H, Kone KM, Zerbo B, Coulibaly YO, Landoure A, Diarra S, Bougoudogo F. Outcome of epidemiological surveillance of bacterial meningitis in Mali from 1996 to 2016: what lesson to learn? J Mol Pathol Epidemiol. 2017;2:02.

23. Amarilyo G. Diagnostic accuracy of clinical symptoms and signs in children with meningitis. Pediatr Emerg Care. 2011;27(3):196-9.

24. Dubos F. Clinical decision rules for evaluating meningitis in children. Curr Opin Neurol. 2009;22(3):288-93.

25. Oostenbrink R. A diagnostic decision rule for management of children with meningeal signs. Eur J Epidemiol. 2004;19(2):109-16.

26. Bonsu BK, Harper MB. Differentiating acute bacterial meningitis from acute viral meningitis among children with cerebrospinal fluid pleocytosis: a multivariable regression model. Pediatr Infect Dis J. 2004;23:511-7.
27. Oostenbrink R. Prediction of bacterial meningitis in children with meningeal signs: reduction of lumbar punctures. Acta Paediatr. 2001;90(6):611-7.

28. Dubos F. Clinical decision rules to distinguish between bacterial and aseptic meningitis. Arch Dis Child. 2006;91(8):647-50.

29. Turczyńska A. Meningitis and encephalitis in Poland in 2008. Przegl Epidemiol. 2010;64(2):189-93.

30. Oordt-Speets AM, Bolijn R, van Hoorn RC, Bhavsar A, Kyaw MH. Global etiology of bacterial meningitis: a systematic review and meta-analysis. PLoS One. 2018;13(6):e0198772. https://doi.org/10.1371/journal.pone.0198772.

31. Antonio M. Seasonality and outbreak of a predominant Streptococcus pneumoniae serotype 1 clone from the Gambia: expansion of ST217 hypervirulent clonal complex in West Africa. BMC Microbiol. 2008;8:198.

32. Leimkugel J. An outbreak of serotype 1 Streptococcus pneumoniae meningitis in northern Ghana with features that are characteristic of Neisseria meningitidis meningitis epidemics. J Infect Dis. 2005:192(2):192-9.

33. Harrison L, Trotter C, Ramsay M. Global epidemiology of meningococcal disease. Vaccine. 2009:27(Suppl 2):B51-63.

34. Saez-Llorens X, McCracken G Jr. Bacterial meningitis in children. Lancet. 2003;361(9375):2139-48.

35. Rothrock S. Pediatric bacterial meningitis: is prior antibiotic therapy associated with an altered clinical presentation? Ann Emerg Med. 1992; 21(2):146-52.

36. American College of Emergency Physicians Clinical Policies, C. and F. American College of Emergency Physicians clinical policies subcommittee on pediatric, clinical policy for children younger than three years presenting to the emergency department with fever. Ann Emerg Med. 2003;42(4):530-45.

37. Negrini B, Kelleher K, Wald E. Cerebrospinal fluid findings in aseptic versus bacterial meningitis. Pediatrics. 2000;105(2):316-9.

38. Kneen $\mathrm{R}$, Solomon $\mathrm{T}$, Appleton $\mathrm{R}$. The role of lumbar puncture in children with suspected central nervous system infection. BMC Pediatr. 2002;2:8.

39. Freedman S. Predictors of bacterial meningitis in the era after Haemophilus influenzae. Arch Pediatr Adolesc Med. 2001:155(12):1301-6.

40. Garges H. Neonatal meningitis: what is the correlation among cerebrospinal fluid cultures, blood cultures, and cerebrospinal fluid parameters? Pediatrics. 2006;117(4):1094-100.

41. Strange G. Meningitis: evidence to guide an evolving standard of care. Pediatr Emerg Med Pract. 2005;2(4):24

42. Bingen E. Bacterial meningitis in children: a French prospective study. Clin Infect Dis. 2005:41(7):1059-63.

43. Samba OS, Milagritos DT, Souleymane D, Mamadou MK, Mariam S, Uma O, Marcela FP, Karen LK, Myron ML. Haemophilus influenzae type b conjugate vaccine introduction in Mali: impact on disease burden and serologic correlate of protection. Am J Trop Med Hyg. 2009:80(6):1033-8.

\section{Publisher's Note}

Springer Nature remains neutral with regard to jurisdictional claims in published maps and institutional affiliations.

\section{Ready to submit your research? Choose BMC and benefit from:}

- fast, convenient online submission

- thorough peer review by experienced researchers in your field

- rapid publication on acceptance

- support for research data, including large and complex data types

- gold Open Access which fosters wider collaboration and increased citations

- maximum visibility for your research: over $100 \mathrm{M}$ website views per year

At $\mathrm{BMC}$, research is always in progress.

Learn more biomedcentral.com/submission 